\title{
Green Synthesis of Iron Oxide Nanoparticles by Using Ficus Carica Leaf Extract and Its Antioxidant Activity
}

\author{
Elvan Üstün ${ }^{1, *}(\mathbb{D})$, Sena Ceren Önbaş ${ }^{1}$, Sakine Kübra Çelik ${ }^{1}$, Melek Çol Ayvaz ${ }^{1}$, Neslihan Şahin ${ }^{2}$ \\ Department of Chemistry, Faculty of Art and Science, Ordu University, 52200, Ordu, Turkey \\ 2 Cumhuriyet University, Faculty of Education, 58140, Sivas, Turkey \\ * Correspondence: elvanustun@odu.edu.tr (E.U.);
}

Scopus Author ID 7003702216

Received: 23.04.2021; Revised: 27.05.2021; Accepted: 2.06.2021; Published: 18.06.2021

\begin{abstract}
In every day, new nanoparticles have been synthesized, and their properties have been evaluated since their unique physical and chemical properties, which are very different from the precursors. Nanoscience also has significant advances in obtaining environmentally friendly and sustainable products. Iron oxide nanoparticles, one of the metal oxide nanoparticles, have different forms and properties. In recent years, iron oxide nanoparticles have been successfully synthesized from various plant species using green synthesis pathways and have been analyzed for different bioactivity properties. In this study, iron oxide nanoparticles were synthesized using a completely non-hazardous method using Ficus carica leaf extract. The synthesized product was characterized by SEM, EDX, XRD crystallography, FT-IR, and UV-Vis spectroscopy. Characterization methods have shown that the product was synthesized in mixed form with 43-57 $\mathrm{nm}$ size. In addition, the antioxidant activity of the product was analyzed, and it was recorded that the nanoparticle has remarkable antioxidant activity.
\end{abstract}

Keywords: green synthesis; iron oxide nanoparticles; antioxidant activity; Ficus carica.

(C) 2021 by the authors. This article is an open-access article distributed under the terms and conditions of the Creative Commons Attribution (CC BY) license (https://creativecommons.org/licenses/by/4.0/).

\section{Introduction}

Nanostructures have led to revolutionary developments in many scientific fields [1]. However, nanoparticle researches are still an intense field since the products have various applications in various fields [2]. Metal oxide nanoparticles have been drawn attention due to their unique and uncommon physical and chemical properties [3, 4]. Furthermore, metal oxide nanoparticles are prominent because of their vital role in many fields such as material chemistry, medicine, agriculture, information technology, biomedical, optics, electronics, catalysis, environment, energy, etc. [5-12]. Decreasing the size of nanoparticles increases the surface area, changes the magnetic, chemical, and electronic properties and metal oxide nanoparticles' characteristics [13]. For example, magnetite type of iron oxide nanoparticles has been used as a contrast agent in magnetic resonance imaging methods and magnetic storage devices [14]. The $\gamma-\mathrm{Fe}_{2} \mathrm{O}_{3}$ nanoparticle with $55 \mathrm{~nm}$ is ferromagnetic, while $12 \mathrm{~nm}$ is superparamagnetic [15]. Therefore, the nanoparticles with the desired size provide expected magnetic, electronic, and chemical properties. 
Iron oxide nanoparticles have been used in many fields such as medicine, biotechnology, environment, photocatalysis since 1990 [16-18]. Magnetite and maghemite $\left(\mathrm{Fe}_{3} \mathrm{O}_{4}\right.$ and $\left.\gamma-\mathrm{Fe}_{2} \mathrm{O}_{3}\right)$ include different oxidation steps of iron and show remarkable physicochemical properties such as high surface area, environmental compatibility, superparamagnetic, and non-toxicity [19]. Iron oxide nanoparticles are synthesized with many methods such as thermal decomposition, sonochemical reaction, hydrothermal applications [20-22]. These methods usually require special equipment and high cost but give low yield [23]. In addition, toxic, corrosive, and flammable chemicals are used during the processes, and the waste solvents and reducing agents that emerged after the synthesis procedures negatively affect both environment and human health [24, 25]. The disadvantages of these traditional methods could be overcome with sustainable and environmental-friendly methods by using natural precursors such as plants, bacteria, seeds, algae [26]. Green synthesis is based on using the seconder metabolites extracted from natural initiator as reducing and stabilizing agent, was first tried by Anastas and Warner in 1998 [27]. The type and part (stem, cell, leaf, seed, etc.), extraction method, and extraction conditions of the natural precursors change the properties of the nanoparticles $[28,29]$. The purification method is also important in the amount and quality of the nanoparticle [30]. In other words, the properties of the synthesized nanoparticles are greatly affected by the experimental conditions, and many iron oxide nanoparticles have been synthesized with many biological sources.

Ficus carica is a diploid species in the Moraceae family and has more than 1400 species divided into about 37 genera [31]. While fruits and leaves of Ficus carica have been used for human consumption for centuries, pharmacological properties of the different parts of the tree have been frequently investigated recently [32-36]. Bioactivities of Ficus carica such as antiviral, antibacterial, antifungal, hypoglycemic, and antimicrobial have been determined, and these properties are due to secondary metabolites such as flavonoids, phenolic compounds, phytosterols, fatty acids [37-39]. Athanasios et al. also noted the presence of psoralen and bergapten in Ficus carica leaf [31].

In this study, iron oxide nanoparticles were synthesized by using fig leaf extracts and characterized by energy-dispersive X-ray spectroscopy (EDX), transmission electron microscopy (SEM), UV-visible spectroscopy, X-ray diffraction (XRD), Fourier transform infrared spectroscopy (FT-IR). The antioxidant activity of these nanoparticles was also evaluated.

\section{Materials and Methods}

\subsection{Apparatus and materials.}

UV-Vis spectra were analyzed with Shimadzu UV-1800 and the Fourier TransformInfrared (FT-IR) spectra were recorded on Shimadzu IR-Affinity spectrophotometer. The surface morphology, elemental composition and size of iron oxide nanoparticles analyzed using a scanning electron microscope (SEM) LEO-EVO 40, equipped with Energy Dispersive X-ray (EDX) Bruker-125 eV. X-ray diffraction (XRD) patterns were measured on a Rikagu RINT-2000. Also, the ultra-pure water obtained from Merck Milli-Q was used throughout all studies.

Iron(III)chloride hexahydrate $\left(97.0 \%, \mathrm{FeCl}_{3} \cdot 6 \mathrm{H}_{2} \mathrm{O}\right)$, sodium hydroxide $(99.5 \%$, $\mathrm{NaOH})$ were purchased from Sigma-Aldrich. All solutions were prepared using ultrapure 
water. All glassware was rinsed using distilled water and air-dried in a hot-air oven before using.

\subsection{Extract preparation.}

Ficus carica leaves were freshly collected, washed twice with tap water and deionized water, and dried in a laboratory oven at $70{ }^{\circ} \mathrm{C}$ for 2 days. The dried leaves were ground into fine particles using a laboratory grinder. $10 \mathrm{~g}$ of the finely divided leaf particles was dissolved in $200 \mathrm{~mL}$ of deionized water in a $500 \mathrm{~mL}$ flat bottom flask. It was heated and stirred in a water bath at $80{ }^{\circ} \mathrm{C}$ for 1 hour. The aqueous leaf extract was filtered using filter paper, put into an amber bottle, and stored in the refrigerator [40].

\subsection{Green synthesis of iron oxide nanoparticles.}

$2.70 \mathrm{~g}(0.01 \mathrm{M})$ of $\mathrm{FeCl}_{3} .6 \mathrm{H}_{2} \mathrm{O}$ was weighed and dissolved with $100 \mathrm{~mL}$ of ultrapure water. The mixture was poured into a bottom flask and heated with a mechanical stirrer at 70 ${ }^{\circ} \mathrm{C} .40 \mathrm{~mL}$ of the plant extract was added in drops to the stirring iron solution. The $\mathrm{pH}$ of the mixture was altered to basic ( $\mathrm{pH}$ of 11) using few drops of $0.1 \mathrm{M} \mathrm{NaOH}$. The mixture was stirred for $1 \mathrm{~h}$. The resulting product was isolated with the centrifuge, severally washed with ultrapure water to remove any unreacted salt and metabolites, and dried in the oven at $80{ }^{\circ} \mathrm{C}$ for 1 day $[41,42]$.

\subsection{Determination of antioxidant activity.}

The antioxidative activity of the resultant product as a nanoparticle was determined with two different assays: DPPH free radical scavenging activity and oxygen radical absorption capacity (ORAC).

To determine DPPH free radical scavenging activity of the nanoparticle, a certain weighable amount of it was added to DPPH (1,1-diphenyl-2-picrylhydrazyl) radical solution prepared in methanol and the mixture was left in the dark for 30 minutes. At the end of this period, the decrease in the amount of free radicals in the tube containing nanoparticles (Abssample) compared to the tube containing no nanoparticles (Absblank) was demonstrated by measuring the absorbance at $517 \mathrm{~nm}$. The same experiment was also performed with standard antioxidant ascorbic acid.

The scavenging activities of both ascorbic acid and nanoparticles were calculated using the following equation in percent. Thus, the DPPH free radical scavenging efficiency of 1 gram of nanoparticles was expressed as ascorbic acid equivalent (mgAAE/g sample).

\section{Scavenging activity $(\%)=\left(\mathrm{A}_{\text {blank }}-\mathrm{A}_{\text {sample }}\right) / \mathrm{A}_{\text {blank }} \times 100$}

In addition, by performing the same experiment in the presence of different amounts of nanoparticles, the amount of nanoparticles sufficient to destroy $50 \%$ of the radical in the environment was expressed as $\mathrm{SC}_{50}$.

The oxygen radical absorbance capacity (ORAC) of nanoparticles as an indicator of antioxidant activity was demonstrated by a spectrophotometric method using pyrogallol red (PGR) [43]. For this method, in the presence of the sample, 12.6 $\mu \mathrm{M}$ PGR was combined with 1.0 mM AAPH (2,2'-Azo-bis(2-amidinopropane) dihydrochloride) used as peroxyl radical source in phosphate buffer $(\mathrm{pH} 7.4,75 \mathrm{mM})$ and after incubation at $37{ }^{\circ} \mathrm{C}$, the decrease in 
absorbance was measured relative to the content of the tube blank without sample. With the help of the graph obtained by performing the same experiment in the presence of various concentrations of Trolox, which acts as a reference antioxidant, the ORAC value of the tested sample was calculated as Trolox equivalent (mg TXE/ g sample)

\section{Results and Discussion}

Morphological screening of synthesized nanoparticles is important in terms of composition and size analysis and SEM analysis was used for this study. SEM images of the synthesized product are presented in Fig.1(a) with a magnification of $100 \mathrm{~K}$ and Fig.1(b) with a magnification of $60 \mathrm{~K}$. The particle size was determined in the range of $43-57 \mathrm{~nm}$. The figures indicate that the nanoparticles get agglomerated and are multiform. Building blocks of various bioactive reducing agents, lower capping ability of leaf extract, H-bonding presented in bioactive molecules could be the reason for the agglomeration of the nanoparticles [44].

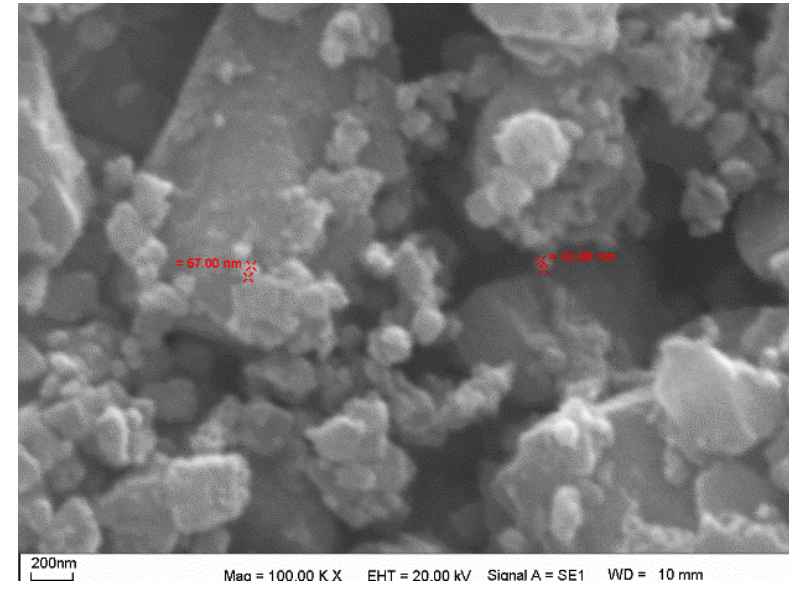

(a)

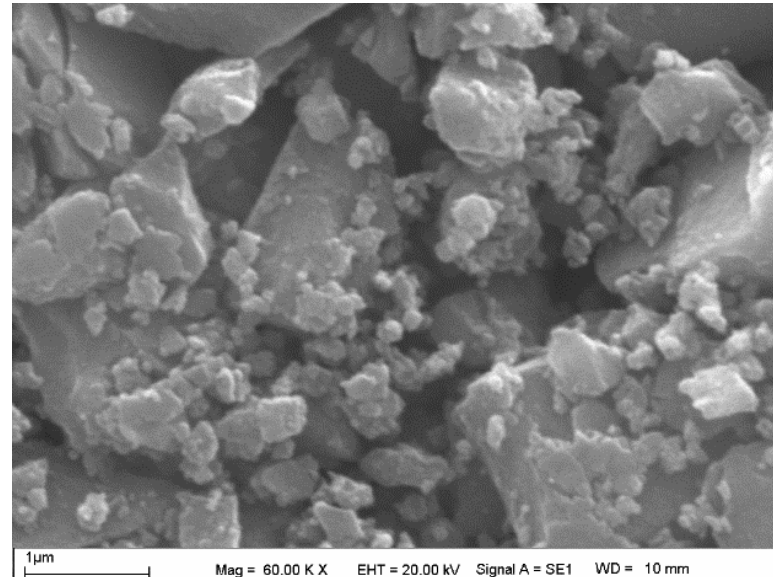

(b)

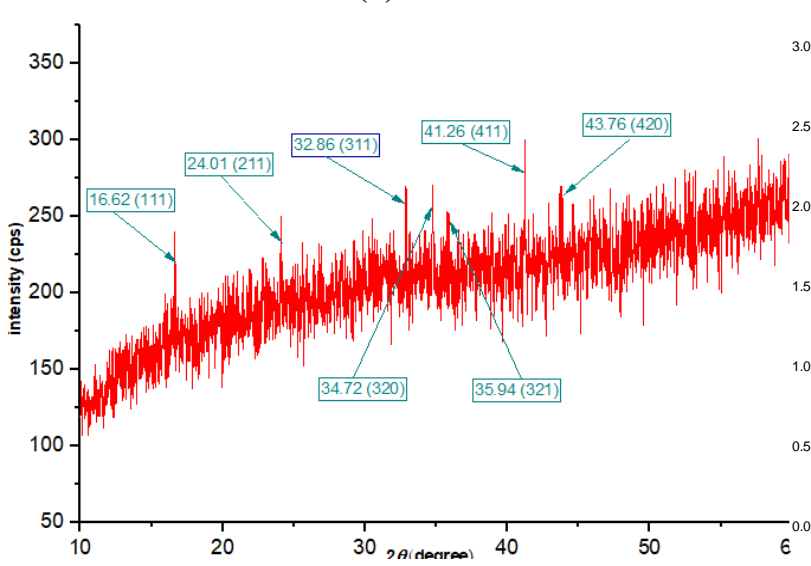

(c)

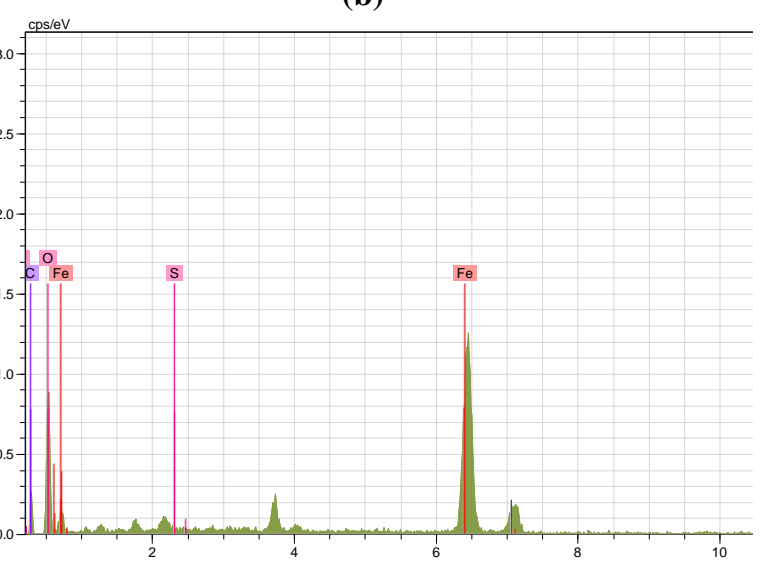

(d)

Figure 1. Characterization of the iron oxide nanoparticle (a) SEM analysis with 100K, (b) SEM analysis with $60 \mathrm{~K},(\mathbf{c})$ XRD analysis, (d) EDX analysis.

$\mathrm{XRD}$ analysis is a characterization method accepted as an essential tool in nanoparticle researches [45]. Similar XRD peaks of iron oxide nanoparticles obtained by green synthesis have been sometimes labeled for a different form. Demirezen et al. reported that the XRD peaks $16^{\circ}$ and $21^{\circ}$ correspond to the crystal face reflection of $\gamma-\mathrm{Fe}_{2} \mathrm{O}_{3}$ [46]. Liu et al. also recorded that the XRD peaks at $14^{\circ}, 27^{\circ}$, and $49^{\circ}$ indicate the lepidocrocite form [47]. Bhuiyan et al. also identified the $26.16^{\circ}, 35.12^{\circ}, 35.12^{\circ}, 36.63^{\circ}, 40.64^{\circ}$ peaks for $\alpha-\mathrm{Fe}_{2} \mathrm{O}_{3}$ nanoparticle [48]. The XRD pattern [Fig.1(c)] of iron oxide nanoparticle showed peaks at $16.6^{\circ}, 24.01^{\circ}$, 
$32.86^{\circ}, 34.72^{\circ}, 35.94^{\circ}, 41.26^{\circ}$, and $43.76^{\circ}$. These results confirmed the multiform of the iron oxide nanoparticles formed by the reduction method using Ficus Carica leaf extract. The two distinct peaks at $2 \theta\left(^{\circ}\right)=16.6^{\circ}$, and $24.01^{\circ}$ which corresponds to phase planes of (111), and (211), respectively, could indicate the $\gamma-\mathrm{Fe}_{2} \mathrm{O}_{3}$ form of the nanoparticle. The XRD peaks at $32.86^{\circ}, 34.72^{\circ}, 35.94^{\circ}, 41.26^{\circ}$, and $43.76^{\circ}$ with the phase plane of (311), (320), (321), (411), and (420) are the indicators of the $\alpha-\mathrm{Fe}_{2} \mathrm{O}_{3}$ nanoparticle.

EDX is an analytical method used to find the chemical compositions of various elements and determines the relative abundance of particular chemical elements on a solid surface [49]. The elemental composition of iron oxide nanoparticles was assessed by EDX analysis, confirming the occurrence of iron as a major metallic element [Fig. 1(d)]. The EDX spectrum determined the presence of iron and oxide. EDX measured the weight percentage of iron $(76.56 \%)$ and oxide $(17.09 \%)$. The synthesized iron oxide nanoparticles had $46.79 \%$ of iron, $36.47 \%$ of oxide and $15.96 \%$ of other elements (carbon and sulfur).

IR spectra of dry Ficus Carica leaf extract and iron oxide nanoparticles were recorded by ATR attachment and these spectra are presented in Figures 2 (a) and (b). The difference between the spectra could be considered as proof of the transformation. The band observed in $3300 \mathrm{~s} \mathrm{~cm}^{-1}$ as hydroxyl, $1635 \mathrm{~cm}^{-1}$ as carbonyl, and $1574 \mathrm{~cm}^{-1}$ as C-H could be labeled in the extracted spectrum [50]. In the IR spectrum of iron oxide nanoparticles which is presented in Figure 2 (b), the band in $3271 \mathrm{~cm}^{-1}$ is considered hydroxyl, while the band in $2962 \mathrm{~cm}^{-1}$ could be considered as the sign of carboxylic acid. The carbonyl band is in $1605 \mathrm{~cm}^{-1}$, while the band in $1065 \mathrm{~cm}^{-1}$ could be evaluated as $\mathrm{C}=\mathrm{C}$ [51]. It has been noted that, in the IR spectra of iron oxide nanoparticles, the bands observed between $400-570 \mathrm{~cm}-1$ have been evaluated magnetite while maghemite has been recorded between 620-660 cm-1 and the bands on $470 \mathrm{~cm}-1$ and $540 \mathrm{~cm}-1$ are considered as hematite [52]. In the recorded IR spectrum (Figure 2(b)), the bands recorded in $470 \mathrm{~cm}-1,501 \mathrm{~cm}-1,555 \mathrm{~cm}-1,594 \mathrm{~cm}-1$ and $633 \mathrm{~cm}-1$ could be the different forms of iron oxide nanoparticles.

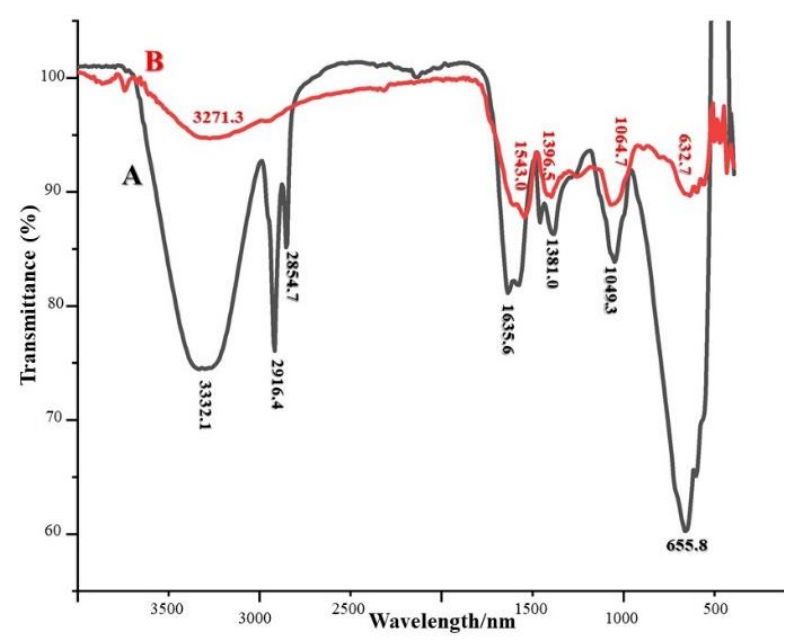

(a)

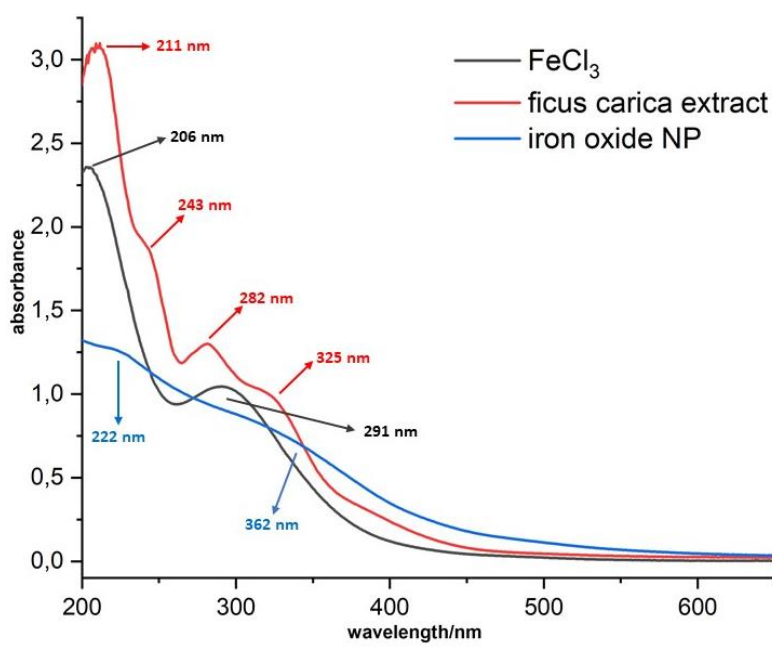

(b)

Figure 2. (a) IR spectrum of Ficus Carica extract (A) and iron oxide nanoparticle (B); (b) UV-Vis spectra of $\mathrm{FeCl}_{3}$ (black), Ficus Carica extract (red), and iron oxide nanoparticle (blue).

UV-Visible spectra of $\mathrm{FeCl}_{3}$, Ficus carica extract and iron oxide nanoparticles are presented in Figure 2(c). The $\mathrm{FeCl}_{3}$ solution shows remarkable UV bands at $291 \mathrm{~nm}$ and 206 $\mathrm{nm}$. On the other hand, many maxima, which correspond to electronic transitions of lots of biological macromolecules, were recorded for Ficus carica. A remarkable UV band considered 
a certain indicator for the iron oxide nanoparticle was not recorded. This may be due to the various electronic transitions of a mixed form of synthesized product. Broad shoulders recorded at $222 \mathrm{~nm}$ and $362 \mathrm{~nm}$ for iron oxide nanoparticles can be analyzed in Figure 2(c).

Two different methods demonstrated the synthesized nanoparticles' antioxidant activity, and it was concluded that they had a remarkable antioxidant activity. Calculated DPPH test results can be used to evaluate the product's ability to trap free radicals. As a result of the DPPH test, it has been calculated that 1 gram of nanoparticles has antioxidant activity equivalent to $5.14 \mathrm{mg}$ ascorbic acid. In addition, it was shown that the nanoparticle at a concentration of $12.118 \mathrm{mg} / \mathrm{mL}$ has an antioxidant capacity that can destroy half of the DPPH radicals in the environment. In other words, we can say that the $\mathrm{SC}_{50}$ value calculated as a result of the DPPH test for the nanoparticle is $12.118 \mathrm{mg} / \mathrm{ml}$. The scavenging efficiency of DPPH radicals of 3 different iron oxide nanoparticles obtained by green synthesis from palm leaf was found between 2 and $26.4 \mathrm{mg} / \mathrm{ml}$ [53].

The ORAC method, which is the other antioxidant activity determination method tested, reveals how many free radicals can be deactivated with the sample tested. The results obtained showed that 1 gram of nanoparticles has an oxygen radical scavenging activity equivalent to $7.360 \mathrm{mg}$ Troloks.

The antioxidant activity of magnetic iron oxide nanoparticles obtained using an inedible Borassus flabellifer seed coat was also evaluated according to 3 different methods. Although an increase in activity was observed with increasing concentration in each method, lower activity values were obtained compared to the standard antioxidant ascorbic acid. Significant cleaning activity of surface-functionalized iron oxide nanoparticles against free radicals can be attributed to the presence of bioactive components with good antioxidant activity in the extract [54].

\section{Conclusions}

The synthesis of eco-friendly and sustainable nanoparticles by using green synthesis methods is promising. Suppose the hopeful developments in nanoparticle studies are evaluated. In that case, the synthesis of nanoparticles from cheap and easy starting materials and the unique properties of every synthesized product will motivate future studies. In this study, iron oxide nanoparticles were synthesized from dried Ficus carica leaves and characterized and their antioxidant activity was analyzed. The recorded activity is remarkable, despite the problem about the synthesis of uniform products in this study. In follow-up studies, the researchers will continue to synthesize nanoparticles with different metal precursors from natural products. It is clear that green synthesized iron oxide nanoparticles should be investigated with advanced studies to be potential candidates in various biomedical applications thanks to their antioxidant activities.

\section{Funding}

This research received no external funding.

\section{Conflicts of Interest}

The authors declare that they have no known competing personal relationships that could have influenced the work reported in this paper. 


\section{References}

1. Xia, Y.; Rogers, J.A.; Paul, K.E; Whitesides, G.M. Unconventional Methods for Fabricating and Patterning Nanostructures. Chem. Rev. 1999, 99, 1823-1848, https://doi.org/10.1021/cr980002q.

2. Stark, W.J.; Stoesse, P.R.; Wohllebenb; W.; Hafner, A. Industrial applications of nanoparticles. Chem. Soc. Rev. 2015, 44, 5793-5805, https://doi.org/10.1039/C4CS00362D.

3. Grassian, V.H. When Size Really Matters: Size-Dependent Properties and Surface Chemistry of Metal and Metal Oxide Nanoparticles in Gas and Liquid Phase Environments. J. Phys. Chem.C. 2008, 112, 1830318313, https://doi.org/10.1021/jp806073t.

4. Vayssieres, L.; Hagfelt, A.; Lindquist, S.E. Three-Dimensional Array of Highly Oriented Crystalline $\mathrm{ZnO}$ Microtubes. Pure Appl. Chem. 2000, 72, 47-52, https://doi.org/10.1021/cm011160s.

5. Chavali, M.S.; Nikolava, M.P. Metal oxide nanoparticles and their applications in nanotechnology. $S N$ Applied Sci, 2019, 1, 607-629, https://doi.org/10.1007/s42452-019-0592-3.

6. Lin, W. Introduction: Nanoparticles in Medicine. Chem. Rev. 2015, 115, 10407-10409, https://doi.org/10.1021/acs.chemrev.5b00534.

7. Iravani, S.; Varma, R.S. Greener synthesis of lignin nanoparticles and their applications. Green Chem. 2020, 22, 612-636, https://doi.org/10.1039/C9GC02835H.

8. Landsiedel R.; Ma-Hock, L.; Kroll, A.; Hahn, D.; Schnekenburger, J.; Wiench, K.; Wohlleben, W. Testing Metal-Oxide Nanomaterials for Human Safety. Adv. Mat. 2010, 22, 2601-2627, https://doi.org/10.1002/adma.200902658.

9. Ziental, D.; Czarczynska-Gonslinska, B; Mlynarczyk, D.T.; Glowacka-Sobotta, A.; Stanisz, B.; Gorlinski, T.; Sobotta, L. Titanium Dioxide Nanoparticles: Prospects and Applications in Medicine. Nanomaterials 2020, 10, 387, https://doi.org/10.3390/nano10020387.

10. Zhang, J.; Mou, L.; Jiang, X. Surface chemistry of gold nanoparticles for health-related applications. Chem. Sci., 2020,11, 923-936. https://doi.org/10.1039/C9SC06497D

11. Lee, S.; Deshpande, R.; Benhammou, D.; Parilla, P.A.; Mahan, A.H.; and Dillon, A.C. Metal oxide nanoparticles for advanced energy applications. Thin Solid Films. 2009, 517, 3591-3595, https://doi.org/10.1016/j.tsf.2009.01.061.

12. Ene, V.L.; Neacsu, I.A.; Oprea, O.; Surdu, V.A.; Trusca, R.D.; Ficai, A.; and Andronescu, E. Single Step Synthesis of Glutamic/tartaric Acid-stabilised Fe3O4 Nanoparticles for Targeted Delivery Systems. Revista de Chimie. 2020, 71(2), 230-238, doi: 10.37358/rc.20.2.7920.

13. Fu, H.; Yao, J. Size Effects on the Optical Properties of Organic Nanoparticles. J. Am. Chem. Soc. 2001, 123, 1434-1439, https://doi.org/10.1021/ja0026298.

14. Tiefenauer, L.X.; Kuehne, G.; Andres, R.Y. Antibody-magnetite nanoparticles: In vitro characterization of a potential tumor-specific contrast agent for magnetic resonance imaging. Bioconjugate Chem. 1993, 4, 347352, https://doi.org/10.1021/bc00023a007.

15. Kim, D.K.; Mikhaylova, M.; Zhang, Y.; Muhammed, M. Protective Coating of Superparamagnetic Iron Oxide Nanoparticles. Chem. Mat. 2003, 15, 1617-1627, https://doi.org/10.1021/cm021349j.

16. Dinali, R.; Ebrahiminezhad, A.; Manley-Harris, M.; Ghasemi, Y.; Berenjian A. Iron oxide nanoparticles in modern microbiology and biotechnology. Crit. Rev. Microbiol. 2017, 43, 493-507, https://doi.org/10.1080/1040841X.2016.1267708.

17. Guo, H.; Barnard A.S. Naturally occurring iron oxide nanoparticles: morphology, surface chemistry and environmental stability. J. Mat. Chem. A. 2013, 1, 27-42, https://doi.org/10.1039/C2TA00523A.

18. Bishnoi, S.; Kumar, A.; R. Selvaraj, R. Facile synthesis of magnetic iron oxide nanoparticles using inedible Cynometra ramiflora fruit extract waste and their photocatalytic degradation of methylene blue dye. Mat. Res. Bull. 2018, 97, 121-127, https://doi.org/10.1016/j.materresbull.2017.08.040.

19. Hu, L.; Percheron, A.; Chaumont, D.; Brachais, C.H. Microwave-assisted one-step hydrothermal synthesis of pure iron oxide nanoparticles: magnetite, maghemite and hematite. J. Sol-Gel Sci. Techn. 2011, 60, 198205, https://doi.org/10.1007/s10971-011-2579-4.

20. Hufschmid, R.; Arami, H.; Ferguson, R.M.; Gonzales, M.; Teeman, E.; Brush, L.N.; Browning, N.D.; Krishnan, K.M. Synthesis of phase-pure and monodisperse iron oxide nanoparticles by thermal decomposition. Nanoscale 2015, 7, 11142-11154, https://doi.org/10.1039/C5NR01651G.

21. Roshan, A.H.; Vaezi, M.R.; Shokuhfar, A.;Rajabali. Synthesis of iron oxide nanoparticles via sonochemical method and their characterization. Z. Particuology. 2011, 9, 95-99, https://doi.org/10.1016/j.partic.2010.05.013. 
22. Takami, S.; Sato, T.; Mousavand, T.; Ohara, S.; Umetsu, M.; Adschiri T. Hydrothermal synthesis of surfacemodified iron oxide nanoparticles. Mat. Letters. 2007, 61, 4769-4772, https://doi.org/10.1016/j.matlet.2007.03.024.

23. Dhivya, S.; Hussain, S.I.; Sheela, S.J.; Kalaiselvam, S. Experimental study on microcapsules of Ag doped $\mathrm{ZnO}$ nanomaterials enhanced Oleic-Myristic acid eutectic PCM for thermal energy storage. Therm. Acta. 2019, 671, 70-82, https://doi.org/10.1016/j.tca.2018.11.010.

24. Dutta, T.; Kim, T.; Vellingiri,K.; Tsang, D.C.W.; Shon, J.R.; Kim, K.;Kumar, S. Recycling and regeneration of carbonaceous and porous materials through thermal or solvent treatment. Chem. Eng. J. 2019, 364, 514529, https://doi.org/10.1016/j.cej.2019.01.049.

25. Narayanasarma, S.; Kuzhiveli, B.T. The effect of silica nanoparticle on thermal, chemical, corrosive, and the nature-friendly properties of refrigerant compressor lubricants-A comparative study. Asia-Pacific J. of Chem. Eng. 2020, 15, 2551, https://doi.org/10.1002/apj.2551.

26. Brindhadevi, K.; Samuel, M. S.; Verma, T.N.; Vasantharaj, S.; Sathiyavimal, S.; Saravanan, M.; Pugazhendhi, A.; Duc P.A. Zinc oxide nanoparticles (ZnONPs) -induced antioxidants and photocatalytic degradation activity from hybrid grape pulp extract (HGPE). Biocatal. and Agr. Bio. 2020, 28, 101730, https://doi.org/10.1016/j.bcab.2020.101730.

27. Anastas, Paul T.; Warner, John C. Green Chemistry Theory and Practice; Oxford University Press: New York, 1998.

28. Bibi, I.; Nazar, N.; Ata, S.; Sultan, M.; Ali, A.; Abbas, A.; Jilani, K.; Kamal, S.;Sarim, F.M.; Khan, M.I.; Jalal,F.; Iqbal M. Green synthesis of iron oxide nanoparticles using pomegranate seeds extract and photocatalytic activity evaluation for the degradation of textile dye. J. Mater. Res. Techn. 2019, 8, 61156124, https://doi.org/10.1016/j.jmrt.2019.10.006.

29. Karpagavinayagam, P.; Vedhi C. Green synthesis of iron oxide nanoparticles using Avicennia marina flower extract. Vacuum. 2019, 160, 286-292, https://doi.org/10.1016/j.vacuum.2018.11.043.

30. Waris, A.; Din, M.; Ali, A.; Ali, M.; Afridi, S.; Baset, A.;Khan A.U. A comprehensive review of green synthesis of copper oxide nanoparticles and their diverse biomedical applications. Inorganic Chem. Com. 2020, 108369, https://doi.org/10.1016/j.inoche.2020.108369.

31. Barolo, M.I.; Mostacero, N.R.; López S. N. Ficus carica L. (Moraceae): an ancient source of food and health. Food Chem. 2014, 164, 119-127, https://doi.org/10.1016/j.foodchem.2014.04.112.

32. Badgujar, S.B.; Patel, V.V.; Bandivdekar, A.H.; Mahajan R.T. Traditional uses, phytochemistry and pharmacology of Ficus carica: a review. Pharma. Bio. 2014, 52, 1487-1503, https://doi.org/10.3109/13880209.2014.892515.

33. Ali, B.; Mujeeb, M.; Aeri, V.; Mir, S.R.; Faiyazuddin, M.; Shakeel, F. Anti-inflammatory and antioxidant activity of Ficus carica Linn. Leaves. Nat. Prod. Res. 2012, 26, 460-465, https://doi.org/10.1080/14786419.2010.488236.

34. Mawa, S.; Husain, K.; Jantan, I. Ficus carica L. (Moraceae): Phytochemistry, Traditional Uses and Biological Activities. Evidence-Based Compl. and Alt. Med. 2013, https://doi.org/10.1155/2013/974256.

35. Gilani, A.H.; Mehmood, M.H.; Janbaz, K.H.; Khan, A.; Saeed S.A. Ethnopharmacological studies on antispasmodic and antiplatelet activities of Ficus carica. J. of Ethn. 2008, 119, 1-5, https://doi.org/10.1016/j.jep.2008.05.040.

36. Salehi, B.; Mishra, A.P.; Nigam, M.; Karazhan, N.; Shukla, I.; Dadasiewicz, A.K.; Sawicka, B.; Głowacka, A.; Abu-Darwish, M.S.; Tarawneh,A.H.; Gadetskaya, A.V.;Cabral, C.; Salgueiro, L.; Victoriano, M.; Martorell, M.; Docea, A.O.; Abdolshahi, A.; Calina, D.; Sharifi-Rad, J. Ficus plants: State of the art from a phytochemical, pharmacological, and toxicological perspective. Phytotherapy Research 2021, 35, 11871217, https://doi.org/10.1002/ptr.6884.

37. Begum, H.A.; Hamayun, M.; Rauf, M.; Gul, H.; Ali, K.; Khan, W.; Schulze, M.; Shah, M. Antimicrobial, antioxidant, phytochemical and pharmacognostic study of the leaf powder of Ficus carica L. Pure Appl. Biol. 2020, 9, 999-100, http://dx.doi.org/10.19045/bspab.2020.90105.

38. Zıd1, K.; Katı, D.E.; Benchikh, Y.; Bey, M.B.; Ouandjeli, D.; Yahiaoui, S. The use of modified atmosphere packaging as mean of bioactive compounds and antioxidant activities preservation of fresh figs (Ficus carica L.) from rare cultivars. The Ann. Uni. Dun. de Jos of Galati. Fascicle VI-Food Tech. 2020, 44, 149-164, https://doi.org/10.35219/foodtechnology.2020.1.09.

39. Ben-Shabat, S.; Yarmolinsky, L.; Porat, D.; Dahan, A. Antiviral effect of phytochemicals from medicinal plants: Applications and drug delivery strategies. Drug Del. Trans. Res. 2020, 10, 354-367, https://doi.org/10.1007/s13346-019-00691-6. 
40. Sandhya, J.; Kalaiselvam S. Biogenic synthesis of magnetic iron oxide nanoparticles using inedible borassus flabellifer seed coat: characterization, antimicrobial, antioxidant activity and in vitro cytotoxicity analysis. Mater. Res. Express. 2020, 7, 015045, https://doi.org/10.1088/2053-1591/ab6642.

41. Kamath, V.; Chandra, P.; Jeppu, G.P. Comparative study of using five different leaf extracts in the green synthesis of iron oxide nanoparticles for removal of arsenic from water. Int. J. Phy. 2020, 22, 1278-1294, https://doi.org/10.1080/15226514.2020.1765139.

42. López-Alarcón, C.; Ortíz, R.; Benavides, J.; Mura, E.;Lissi, E. Use of the ORAC-pyrogallol red/ORACfluorescein ratio yo assess the quality of antioxidants in chilean wines. J. Chil. Chem. Soc. 2011, 56, 764767, http://dx.doi.org/10.4067/S0717-97072011000300009.

43. Devi, H.S.; Boda, M.A.; Shah, M.A.;Parveen, S.; Wani, A.H. Green synthesis of iron oxide nanoparticles using Platanus orientalis leaf extract for antifungal activity. Green Process Synth. 2019, 8, 38-45, https://doi.org/10.1515/gps-2017-0145.

44. Rao, N.H.; Lakshmidevi, N.; Pammi, S.V.N.; Kollu, P.; Ganapaty, S.; Lakshmi, P. Green synthesis of silver nanoparticles using methanolic root extracts of Diospyros paniculata and their antimicrobial activities. Mat. Sci. Eng. C 2016, 62, 553-557, https://doi.org/10.1016/j.msec.2016.01.072.

45. Anooj, E.S.; Praseetha, P.K. Green Synthesis and Characterization of Graphene Quantum Dots from Rosa Gallicapetal Extract. Plant Arch. 2020, 20, 6151-6155.

46. Demirezen, D.A.; Yıldız, Y.Ş.; Yılmaz, D.D. Amoxicillin degradation using green synthesized iron oxide nanoparticles: Kinetics and mechanism analysis. Env. Nanotechn. Mon. \& Man. 2019, 11, 100219, https://doi.org/10.1016/j.enmm.2019.100219.

47. Liu, A.; Liu, J.; Pan, B.; Zhang W. Formation of lepidocrocite $(\gamma-\mathrm{FeOOH})$ from oxidation of nanoscale zerovalent iron (nZVI) in oxygenated water. RSC Adv. 2014, 4, 57377-57382, https://doi.org/10.1039/C4RA08988J.

48. Bhuiyan, S.H.; Miah, M.Y.; Paul, S.C.; Aka, T.D.; Saha, O.; Rahaman, M.; Sharif, J.I.; Habiba, O.; Ashaduzzaman, M. Green synthesis of iron oxide nanoparticle using Carica papaya leaf extract: application for photocatalytic degradation of remazol yellow RR dye and antibacterial activity. Heliyon. 2020, 6, e04603, https://doi.org/10.1016/j.heliyon.2020.e04603.

49. Dhivya, S.; Hussain, S.I.; Kalaiselvam, S. Novel metal coated nanocapsules of ethyl esters fatty acid eutectic mixture as phase change material with enhanced thermal conductivity for energy storage applications. Therm. Acta. 2020, 687, 178581, https://doi.org/10.1016/j.tca.2020.178581.

50. Betancur, A.; Correa, M.; Perez, F.R.; Barrero C.A. Quantitative approach in iron oxides and oxihydroxides by vibrational analysis. Opt. Pura Apl. 2012, 45, 269-275, http://dx.doi.org/10.7149/OPA.45.3.269.

51. Sandya, J.; Veeralakshmi, S.; Kalaiselvam, S. Tripolyphosphate crosslinked Triticum aestivum (wheatgrass) functionalized antimicrobial chitosan: Ameliorating effect on physicochemical, mechanical, invitro cytocompatibility and cell migration properties. J. Biomol. Struct. Dyn. 2021. 39, 1635-1644, https://doi.org/10.1080/07391102.2020.1736160.

52. Demirezen, D.A.; Yıldız, Y.S.; Yılmaz, Ş.; Yılmaz, D.D. Green synthesis and characterization of iron oxide nanoparticles using Ficus carica (common fig) dried fruit extract. J. Biosci. Bioeng. 2019, 127, 241-245, https://doi.org/10.1016/j.jbiosc.2018.07.024.

53. Abdullah, J.A.A; Eddine, L.S.; Abderrhmane, B.; Alonso-González, M.; Guerrero, A.; Romero, A. Green synthesis and characterization of iron oxide nanoparticles by pheonix dactylifera leaf extract and evaluation of their antioxidant activity. Sustainable Chemistry and Pharmacy. 2020, 17, 100280-100286, https://doi.org/10.1016/j.scp.2020.100280.

53. López-Alarcón, C; Denicola, A. Evaluating the antioxidant capacity of natural products: A review on chemical and cellular-based assays.Anal. Chim. Acta. 2013, 763, 1-10, https://doi.org/10.1016/j.aca.2012.11.051. 